\title{
Evaluation of Saving Energy by Using the Power of Plant Composites as a Thermal Insulation; A case study: Effect of a Local Date Palm Fibers
}

Firouzeh Hajihosseini ( $D$ Firouzeh.hosseini88@gmail.com )

Art University of Tehran https://orcid.org/0000-0001-8287-469X Jafar Mahmoudi

KTH/School of Industrial Engineering and Management/Dept. of Sustainable Production Development, Sweden

\section{Research Article}

Keywords: Sustainable material, Optimization, Date palm fiber, Green Building

Posted Date: January 18th, 2022

DOI: https://doi.org/10.21203/rs.3.rs-1266409/v1

License: (c) (i) This work is licensed under a Creative Commons Attribution 4.0 International License.

Read Full License 


\section{Abstract}

This research focuses on assessing the potential use of the power of local palm fiber (Zahedi) as an ecofriendly composite in order to help the sustainable development. Local date palm fibers are separated into individual fibers and washed in water and then heated in an oven at $60^{\circ} \mathrm{C}$ to dry completely in order to investigation of physical properties. The developed composites were characterized in different ratio and compared in terms of physical and morphological properties. Afterwards, the analysis of scanning electron microscopy (SEM) and dispersive energy spectroscopy (EDS) from date palm fibers of Zahedi was carried out to determine the chemical and microstructure composition of the fibers. It was found that carbon and oxygen, are the only compatible and primary compounds in this palm fiber. Analyzing in the longitudinal direction of the fibers, it can be mentioned that the surface of the samples in nanoscale is irregular with many impurities, cells and pores. Also, the Scanning Electron Microscopy analysis of the fiber diameter shows the average range of the diameter is 107-135 $\mu \mathrm{m}$. Plant-based composites were characterized in seven ratios by combining the date palm fibers with industrial cornstarch as a matrix which creates the insulator composite totally natural. The amount of thickness swelling and water absorption observed in this study was approved and appropriate for a volume ratio of 1:1 in comparison with other studied compounds. The thermal resistance of the three specimens tested by experiment. To evaluate the insulation capability, the specimens were placed at a chamber in a position to act as an obstacle to the thermal transmission. In this case, by increasing the temperature up to $80^{\circ} \mathrm{C}$ on one side (inside the chamber) and recording the temperature rise on the opposite side, the thermal insulation ability of the specimens was assessed. According to the results of the practical experiments, combining date palm fiber (DPF) with cornstarch resin as a matrix illustrated that the composite material is applicable, safe and useful as a thermal insulation material at a maximum of $80^{\circ} \mathrm{C}$ which is appropriate for preventing heat transfer in buildings.

\section{Introduction}

Today, the use of heat-resistant materials, especially in buildings, has been a fundamental issue in the construction industry with the aim of saving energy (Djoudi, 2014). Saving energy in buildings is used as a way to decline energy consumption, carbon emissions, and their destructive effects on our living environment (Cao, 2016). One of the factors in saving energy is attention to heat transfer that change the temperature through the walls by the process of conduction and radiation (Oshabi, 2015). Currently, most wall insulation materials are made from mineral wool, expanded polystyrene, or polyurethane. Although these materials have good physical properties, including low thermal conductivity and fire resistance, they are very expensive and hazardous to environmental and human health (Morad, 2013). These substances may be the cause of environmental hazards. Small particles of fiberglass insulation can pose a health hazard and irritate the breath or skin (Occupational Safety and Health Organization, 2003). these fibers may cause coughing and sore throat. (Infante, Schuman, \& Dement, 1994). Most thermal insulations contain formaldehyde resin which can affect sensitive individuals and cause asthma (US Environmental Protection Agency, 2000). Cellulose insulation with toxic chemicals, such as boric acid, has been reported 
to be harmful to human health (US Department of Occupational Safety and Health (OSHA), 1999). The harmful nature and high cost of making these composites have made research activities in recent times necessary to find alternative thermal insulation products.

Natural fibers, as a good alternative, have attracted the attention of scientists and researchers due to their environmentally friendly properties, which makes them known as potential reinforcers in polymer composites instead of synthetic fibers. (K.I.Alzebdeh, 2017). The thermal effect of these insulating materials is comparable to ordinary, mineral, and glass fiber-based products. Extensive research on the features of plant thermal insulation has shown that these materials have good thermal insulation properties compared to commonly used insulation materials such as mineral wool, expanded polystyrene, and polyurethane. In the case of bio-based resources, the possibility of providing a new source of income for domestic agriculture can be an important factor in the production and use of bio-based materials. (Steffensa, 2017).

Nowadays, one of the good bio-based materials is a tropical tree of date palm found primarily in the Middle East. According to the UN Food \& Agriculture Organization (FAO), the Persian Gulf countries account for approximately 50 percent of the global date production (Wet. FAO, 2018). There are more than 3,000 species of date palms around the world including 250 in Tunisia, 370 in Iraq and 244 in Morocco. Among countries, Iran has the largest number of palm species by about 400 species. (Zaid, 2002) and has the potential to use date fibers in industrial applications. The southern provinces of the country such as Khuzestan, Sistan and Baluchestan and Bushehr are among the major producers of this product. Therefore, by using these fibers as a reinforcer, it is possible to produce high-value products from a cheap and low-cost material, and by doing so, it can significantly contribute to the environment and the agricultural industry. In Iran, the area of date palm groves is estimated at 22 hectares, which is about 20 to $22 \%$ of the world's groves. In order to harvest quality dates, palms must be pruned every year. The average waste from pruning each palm is about 17 to $34 \mathrm{~kg}$, which, considering about 27 million palm trunks in the country, produces at least $270,000 \mathrm{~kg}$ of waste per year, which is not currently used industrially. (M.Karizaki, 2017) In Iran, palm fibers were used to make a local rope named Sis. Also, the elastic property of palm fibers was applied to strengthen the corners of the king dome in the Bam, historical Citadel which shows the good properties of this material against tensile force. (Barsam, 2019).

Recently, lots of study has been done comprehensively and extensively on the study of properties of palm fiber. Some recently reported about of date material compositions are presented in Table 1. In the research by Salih and et al, the properties of palm tree wastes have been investigated in two ways. The first factor examined the tensile properties of four parts of the stem, spike, trunk and leaf and the second factor tested the fiber length effect in three different sizes. The results of these two studies have shown that among the four mentioned sections, palm tree leaves and among three different sizes, $20-40 \mathrm{~mm}$ size have caused the highest tensile strength in the composite. Also, one investigation of the thermal properties of the fiber was made in a species of the local Palm of Morocco which the results have shown that these fibers, have the capability of retaining oxygen and can be mentioned as a natural insulation (B. Beighi, 1998). 


\begin{tabular}{c|c|c}
\hline Date palm fibers & Polymer Matrix & References \\
\hline DPF (petiole, bunches and rachis) & Gypsum & (Chikhi, 2016) \\
\hline Date palm spikelet & Mortar & (Abdelazizab, 2016) \\
\hline Hybridized date palm leaf/Glass fibers & Epoxy & (Gheith, et al., 2019) \\
\hline stem, spike, trunk and leaf & - & (Dr. Sihama E.Salih, 2013) \\
\hline Date palm mesh fibers & Cement-based mortar & (Benaimeche, et al., 2018) \\
\hline Date palm fiber & phenolic resin & (Kashizadeh, 2019) \\
\hline DPF/Graphite filler & Epoxy & (Shalwan \& Yousif, 2014) \\
\hline Date palm wood flour (rachis, leaflet and leaf) & Polyethylene & (Mirmehdi, et al., 2014) \\
\hline Date palm wastes Linear & Low density polyethylene matrix & (Alshabanat, 2019) \\
\hline Hybridized date palm and flax fibers & Thermoplastic starch & (Ibrahim, et al., 2014) \\
\hline Date palm fibers & & \\
\hline
\end{tabular}

Table.1: Reported studies on date palm composites.

However, there is insufficient information on the various physics-related properties of such insulating materials. Thus, the purpose of this study is to evaluate the feasibility of using the local date palm fibers harvested from a southern region in Iran, as a plant-based composite material for the reduction of heat loss in air conditioning zones. In addition, this paper discusses the suitability of DPF for thermal insulation by examining thermal resistance and morphological characteristics. The need for alternative wastes is inevitable due to the rapid depletion of natural resources. The new plant-based insulating material differs from other materials in the literature data that have produced similar materials using cornstarch as an adhesive.

\section{Experimental Procedure}

\subsection{Materials and process}

Date palm fibers used in this study were harvested in 2019. These materials are date palm fibers (DPF) of Zahedi (Local name), collected from the province of Kerman in Iran (Figure. 1) The main production of Zahedi dates is in a region called Posht Kuh in Bushehr province. This kind of palm can be transported and stored conveniently, due to its dry nature. Also, it has a long shelf life of about two years in cold and dry places. (M.Karizaki, 2017). Date palm fiber (DPF) has a natural texture and is pulled out from the top of trunk of palm tree in a form of nearly mesh and almost rectangular mesh (30 to $50 \mathrm{~cm}$ length and 20 to $30 \mathrm{~cm}$ width) and several layers from the tree trunk. This mesh network can be separated into independent fibers with diameters from 0.1 to $0.8 \mathrm{~mm}$ shown in the figure 2 .

\subsubsection{Mechanical properties:}

Mechanical properties are physical features that a material shows upon the application of forces. Mechanical properties of plant-based composites depend on the feature of the fiber. Even a small change in the physical character of the fiber in composite may result in significant changes in the overall 
mechanical properties of composites. Modulus of elasticity, tensile strength, elongation are examples of mechanical features. Fibers with different lengths of 20,30 and $40 \mathrm{~mm}$ were used. The mechanical properties of fibers are shown in the table 2.

\begin{tabular}{cccc}
$\begin{array}{c}\text { Specimen's length } \\
(\mathrm{mm})\end{array}$ & $\begin{array}{c}\text { Tensile strength } \\
(\mathrm{Mpa})\end{array}$ & $\begin{array}{c}\text { Elongation } \\
(\%)\end{array}$ & $\begin{array}{c}\text { Elasticity modulus } \\
(\mathrm{GPA})\end{array}$ \\
\hline 20 & $290 \pm 20$ & $11 \pm 2$ & $5.25 \pm 3$ \\
50 & $245 \pm 30$ & $12 \pm 2$ & $5.00 \pm 2$ \\
\hline 100 & $170 \pm 4$ & $16 \pm 3$ & $4.74 \pm 2$
\end{tabular}

Table.2: Mechanical properties of fibers

\subsubsection{Composite preparation:}

In this research, the fibers are separated from a surface of the palm tree trunk. Using a cutting mill with a sieve of $20 \mathrm{~mm}$ mesh, grinding of date palm fibers was done. various particle sizes were obtained from 20 to $100 \mathrm{~mm}$ and saved at room temperature $\left(25^{\circ} \mathrm{C}\right)$. For the combination with industrial cornstarch, fibers were finally selected in pieces $20 \mathrm{~mm}$ long (Figure.3). The grinding machine is used for the agricultural wastes, which were ground in a mixture of corn starch. The production steps and typical insulating composite specimen produced $(25 \times 25 \times 8 \mathrm{~cm}$ in size) is presented in the figure 4 .

Using a length of $20 \mathrm{~mm}$ due to the high modulus of elasticity and cornstarch, the samples were obtained in the volume ratio of $1: 1,1: 2,1: 3,2: 3,2: 1,3: 1,3: 2$. To make the insulation material natural, industrial cornstarch was applied as a matrix and bind to fibers. About $90 \%$ of the volume of consumption by cornstarch products are used to make paper and paperboard because of its elasticity; in tile manufacture of textiles; field as adhesives in making cardboard, cartons, boxboard, insulation board, and gummed labels and tapes. (Russell, 1973) Other items are for making sample mixers and square molds without holes.

\subsubsection{Density:}

Using a length of $20 \mathrm{~mm}$ due to the high modulus of elasticity and cornstarch, the samples were obtained in the ratio of $1: 1,1: 2,1: 3,2: 3,2: 1,3: 1,3: 2$. Seven samples were tested and the results of the tested samples were presented (figure 5 , figure 6 , table 3 ). Density was determined according to BS EN 323: 1993 using Eq:
(1)
D: $\frac{M}{V}$ 
Where $\mathrm{M}$ is the mass and $\mathrm{V}$ is the volume of the composite sample. The relationship between fibers and resin is presented in the figure 7. To show the graph appropriately, the amount of density was divided by 100.

\begin{tabular}{llllllll} 
Specimen number & $\mathbf{1}$ & $\mathbf{2}$ & $\mathbf{3}$ & $\mathbf{4}$ & $\mathbf{5}$ & $\mathbf{6}$ & $\mathbf{7}$ \\
\hline Cornstarch (Gram) & 3000 & 2000 & 3000 & 1000 & 2000 & 1000 & 1000 \\
\hline Date palm fiber (Gram) & 650 & 650 & 1300 & 650 & 1950 & 1300 & 1950 \\
\hline Density (Kg/m3) & 1143 & 1065 & 1047 & 992 & 798 & 760 & 720 \\
\hline Weight ratio of DPF to Cornstarch & 0.22 & 0.33 & 0.43 & 0.65 & 0.98 & 1.30 & 1.95 \\
\hline Volume ratio of DPF to Cornstarch & $1: 3$ & $1: 2$ & $2: 3$ & $1: 1$ & $3: 2$ & $2: 1$ & $3: 1$
\end{tabular}

Table 3: Prepared sample in deferent proportion.

\subsubsection{Thermodynamic properties:}

The aim of a temperature test is to verify the resistance of a specimen to the environmental influence of temperature. In this study, mini-desktop temperature test chamber is the apparatus to test temperature resistance. These series are manufactured under the (ATM) model and are designed for setting in laboratories suffering from lack of space or want to test their smallest size, parts, materials and productivity at the lowest cost. This model of chambers with a minimum temperature of -40 and -70 and a maximum temperature of $+180^{\circ} \mathrm{C}$. are available in sizes 37,55 and 75 liters, (Figure 8). To evaluate the insulation capability, the specimens are placed in a position to act as an obstacle to the thermal transmission. Then, by increasing the temperature up to $80^{\circ} \mathrm{C}$ on one side (inside to the chamber) and recording the temperature rise on the opposite side, the thermal insulation ability of the samples is assessed.

\subsubsection{Water Absorption:}

Test Water absorption tests were carried out for each specimen, with dimensions of $40 \mathrm{~mm} \times 40 \mathrm{~mm} \times 50$ mm, as per ASTM D 570-98 (2018). This experimental system to study water absorption has a duty to test of control over the uniformity of a product. This function is especially useful for sheet, rod and tube arms when tested on the final product. The initial specimen's weight (Wd) was measured and recorded before immersion in water. Then, specimen weight $(\mathrm{Wn})$ was measured again and noted each 24 hours for a week. The water absorption percentage of the composites were counted using Equation (2):

Water absorption $=(\mathrm{W} n-\mathrm{W} d) / \mathrm{W} \mathrm{d} \times 100(\%)$ 
Where Wn is the specimens' weight after immersion into the water and Wd is the specimens' weight before immersion into water.

\subsubsection{Thickness Swelling Test:}

Thickness swelling of each composite sample, with dimensions of $40 \mathrm{~mm} \times 40 \mathrm{~mm} \times 50 \mathrm{~mm}$, was assessed according to ASTM D 570-98 (2018). The initial thickness of all seven samples was recorded before placing them in distilled water. By immersing the samples for one week, the thickness of the samples was recorded every 24 hours. The thickness swelling of the specimens was done using Equation (3):

Thickness swelling $(\square)=(\mathrm{T} 1-\mathrm{T} 0 / \mathrm{T} 0) \times 100$ (3)

Where T0 is the thickness before soaking and the thickness of specimen after soaking is T1.

\subsubsection{Morphological analysis (SEM and EDS analysis)}

Using Nova Nano SEM 450 (SEM) scanning electron microscope, microscopic studies were performed. Energy dispersive spectroscopy (EDS) was applied to analyze the chemical combination of palm fiber samples using Nova Nano SEM 450. (Figure 9)

Energy dispersive spectroscopy (EDS) was applied to analyze the chemical composition of palm fiber samples using Nova Nano SEM 450. (Figure 9) The EDS process illustrates x-rays emitted from the specimen when they are bombarded by an $\mathrm{x}$ - ray to specify the elemental combination. properties of materials can be tested in scale of $1 \mu \mathrm{m}$ or less. When the specimen is bombarded by electron beam, electrons are emitted from the atoms containing the sample's surface. The resulting electron vacancies are completed by electrons from a higher state, and an x-ray is emitted to balance the energy division between the two electrons' states. The x-ray energy is a feature of the element from which it was emitted.

The EDS X-ray detector illustrates the relative frequency of the emitted X-rays in comparison with their energy. The detector is mainly lithium-containing silicon. This detector converts electrons reflected by the sample surface into a signal that can be viewed as images on a monitor. When the X-ray hits the detector, it generates a rod pulse equal to the X-ray energy. The bar pulse is transformed to a voltage pulse by a charge-sensitive preamplifier. The signal is then transmitted to a multi-channel analyzer in which the pulses are sorted by voltage. The amount of energy determined in each measurement is sent to the computer as an X-ray image to display and evaluate the data. The spectrum of X-ray energy is evaluated to determine the elemental combination of the sampled volume. Using a process known as X-ray mapping, information about the elemental combination of a sample can then be overlaid on top of the magnified image of the sample (Wiley, 2015).

\subsubsection{Thermal conductivity}


Heat transfer occurs in objects when a temperature gradient is created between two points in objects. To create this gradient, the sample was placed in a heat resistance machine and by installing four thermocouples in the four corners of the sample for 140 minutes up to a maximum temperature of 80 degrees, the heat transfer rate between the two surfaces of the sample is tested. Also, the thermal conductivity of samples is determined using comparison with literary data. According to the report of Agoudjil et al, these parameters have been obtained at room temperature with their corresponding statistical confidence bounds (Agoudjil, 2011).

\section{Results And Discussion}

\subsection{Structure and morphology}

In order to investigate the structure of pores and their distribution, the Nova Nano SEM 450 scanning electron microscope with a working voltage of 0.30 / $30 \mathrm{kV}$ was applied to observe the surface structure of palm fibers. Prior to observation, a small portion of the fibers was prepared and mounted on an aluminum foil with a thin layer of gold to prevent electrostatic charge during the SEM examination. The elemental samples of date palm fibers were determined from the peak areas of the trunk. These figures illustrate SEM images of a sample Zahedi- DPF in a longitudinal direction of fibers is scaled from 500 to $5 \mu \mathrm{m}$. Examining the nanostructures in the samples, it is observed that the surface of the samples is irregular with many impurities, cells, and pores (figure.10). The results presented in figure 12 show the presence of oxygen and carbon atoms with significant atomic percentages and carbon is the predominant element that confirms the presence of cellulosic carboxylic groups. Carbon and oxygen are two major elements with $51.40 \%$ and $44.72 \%$ respectively. Other minor components in the test obtained from the analysis included sodium, magnesium, silicon, sulfur, and calcium. Figure 11 shows the irregular surface of fibers with many cells, which allows for proper adhesion between the fiber and the matrix and refers to the porous structure of the fibers, which confirms their hydrophilic properties.

\section{4-2. Energy dispersive spectroscopy (EDS) results}

The images above (Figure 12) show the spectrum obtained from the analysis of a sample of date fiber material by EDS X-ray. The energy of each of the peaks shown in this diagram is assigned to a specific atom. Also, the number of elements in the sample based on weight and atomic percentages is shown below the figures. In this experiment, two different points of the fibers were analyzed: the first point was related to the outer part of the fiber. It was detected that carbon and oxygen are the main compatible compounds in this date with 51.40 and $44.72 \%$ atomic percentages, respectively, the only permanent and essential components in palm fiber. The second point tested is basically made of fewer compounds, but The two elements, carbon and oxygen were also observed as permanent components of the fibers.

\subsection{Water Absorption:}

Figure 13 shows the percentage of water uptake of date / corn starch fiber compounds. It is clear that the DPF composition in the corn starch matrix rises their water uptake values as the immersion time 
increases, as the samples become saturated after approximately eight days. This behavior can be interpreted by the hydrophilic character of palm fiber, which is due to the existence of polar groups that form a strong hydrogen bond between cell and water molecules.

This behavior can be explained by the fact that water uptake is generally affected by the presence of pores, cracks, holes, cavities, defects, poor surface adhesion and micro cracks at the interface between the DPF and the cornstarch matrix. Strong adhesion shows less space in the composites, which can store water molecules and thus reduce water absorption. In contrast, more water absorption leads to the creation of micro cracks, which eventually leads to cavities and free space inside the composites due to the swelling of the fibers. The void / free space created contributes to the potential failure mechanism of these composites.

\subsection{Thickness Swelling Test:}

From Figure 14, it can be also observed that the specimen No.7 shows higher thickness swelling behavior. These statements are also in line with those of other researchers such as Edhirej, A et al and Senthil Kumar, $\mathrm{K}$ et al. Significantly, research has shown that swelling minimizes the surface adhesion thickness that affects mechanical properties. In fact, the thickness swelling and water absorption of palm fiberreinforced composites are two of their basic pitfalls since the existence of humidity results in the breakdown of the fiber-matrix surface or in delamination, fiber separating and, finally, the creation of micro voids and interfacial gaps induced by moisture which, in turn, affect their mechanical features. Supplementary to this, the statements have been studied and reviewed by other researchers.

\subsection{Thermodynamic Test}

Regarding to the results of water absorption and swelling thickness three specimens were opted to investigate the heat resistance test. considering the minimum, moderate and maximum percentages of water absorption and swelling thickness, samples examined were No.1, No.4 and, No.7. The results are shown in the figure 15. To make a same condition for comparing, each specimen was exposed to $80.3^{\circ} \mathrm{C}$ temperature in the hot side. Among three specimens, No.1 witnesses the maximum temperature of 35.7 ${ }^{\circ} \mathrm{C}$ in the cold side during the 142.5 minutes. For Specimen No.4 and No.7 the maximum temperature of the cold side during the experiment was $24.4^{\circ} \mathrm{C}$ and $36.6^{\circ} \mathrm{C}$ at the same time, respectively.

\section{4-5.1 Investigation of thermal resistance on the optimal specimen}

As is mentioned, the goal of this experiment is to assess the feasibility of applying the mixture of palm fibers and cornstarch, as a plant-based composite material for the reduction of heat loss in air conditioning zones. To prepare the desired composite, the industrial starch was mixed with a suitable percentage of date palm fibers (DPF) in a volume ratio of 1:1, and after soaking the starch particles and fibers, the mixture is kneaded well to remove the air bubbles trapped inside it. In this way, the hardness of the composite also increases. DPF and cornstarch should first be dry-mixed to have a uniform color on a clean masonry platform and then mixed by adding clean water slowly and gradually to have consistency. 
In order to evaluate the insulation capability, the specimen was placed at a chamber in a position to act as an obstacle to the thermal transmission. In this case, by increasing the temperature up to $80^{\circ} \mathrm{C}$ on one side (inside to the chamber) and recording the temperature rise on the opposite side, the thermal insulation ability of the specimen was assessed. The thermal resistance test was performed by increasing the burner output both gradually and rapidly over a specified period of time. The graph shown (Figure.16) is the result of a thermal resistance test. In the vertical axis the temperature is from zero to 90 degrees Celsius and in the horizontal axis the time is up to 160 minutes, the red graph presents the heat transferred to the hot side surface and inside the furnace and the blue graph shows the cold surface temperature. The wall between these two surfaces is completely vacuumed to prevent heat loss. As shown in the figure, by increasing the burner output at the hot surface, the heated surface temperature first reaches linearly up to $40^{\circ} \mathrm{C}$ in the first 8 minutes. Then, the temperature is gradually increased, with a gentle slope and downward concavity to about $60^{\circ} \mathrm{C}$ in 80 minutes. While the temperature on the hot side rises to $80^{\circ} \mathrm{C}$ with a steep slope and is still exposed to a maximum temperature of $80^{\circ} \mathrm{C}$ for 42 minutes, only a slight change is observed in the cold surface of the sample, which also It can be ambient temperature fluctuations in the chamber inside the device. The maximum temperature of the cold side during the experiment is $24.4^{\circ} \mathrm{C}$. In general, this process means that this composite material can be used as a thermal insulation material below $80^{\circ} \mathrm{C}$, is safe and useful, which can be suitable for use to prevent heat transfer in construction application.

As it was determined from the results of the EDS analysis, carbon and oxygen are the only permanent and fundamental components in these materials proved by the EDS test of Zahedi-DPF. In the study by Agoudjil et al, the constituent elements in the fibers of several palm species in Morocco were examined with the SEM apparatus. In table (4) "Zahedi" species with its constituent elements as well as the weight percentage of each element is written in the first row of the table. The other species tested by Agoudjil et al are also listed under Zahedi species, respectively. To better compare between these species, all the constituent elements of the species are shown in figure 16, and then the closest species to Zahedi fibers in terms of weight percentage of constituent elements are specified separately (figure.17).

As is mentioned in the figure 17, the literature data showed the medium value of quantification EDS tests for each variety and part of date palm samples. Also, in the graph below, it can be seen the amount of Carbon and Oxygen as primary elements and other components in the Zahedi-DPF and the petiole of Elghers, PEG, are relatively similar to each other. This can be attributed to the similar chemical composition of the soil environment and local climate in which the plants are growing. By comparing the numbers of elements reported by Agoudjil et al (Agoudjil 2011) with those of in this case study, the thermal conductivity of PEG (Petiole of Elghers-variety) is approximately similar to that of DPF of Zahedi. Hence, according to the table (5), the thermal conductivity of the sample studied in this work is approximately $0.072 \mathrm{~W}(\mathrm{Wm}-1 \mathrm{~K}-1)$ at atmospheric pressure (Table 5). This is close to the thermal conductivity of many insulator materials, such as wood fiber insulation boards, which are used for thermal and acoustic insulation on ceilings, walls or floors. However, most of the board insulations are a combination of materials with different functions. Since DPF is a good material to improve the tensile and flexural strength in plasterboards it can be also used as an improver for other natural materials 
(Azami 2015). Therefore, due to the similarity of its constituent elements with the species studied in this study (Zahedi species), the thermal resistance of Zahedi species can be estimated approximately. Therefore, with these conditions, it is possible to prepare and test the natural insulation composite from the desired fibers and natural resin, assuming that these fibers have the ability to resist heat transfer.

\begin{tabular}{|c|c|c|c|c|c|c|c|}
\hline \multirow{2}{*}{ VARIETY } & \multicolumn{7}{|c|}{ ELEMENTS } \\
\cline { 2 - 9 } & $\mathrm{c}$ & $\mathrm{o}$ & $\mathrm{ca}$ & $\mathrm{si}$ & $\mathrm{s}$ & $\mathrm{mg}$ & na \\
\hline ZAHEDI & 51.4 & 44.72 & 2.28 & 0.86 & 0.39 & 0.22 & 0.13 \\
PDN & 43.95 & 47.08 & 0.75 & 0.69 & 0.13 & 1.52 & 0.23 \\
BDN & 42.67 & 48.19 & 0.12 & 0.28 & 0.37 & 0.04 & 0.03 \\
PMD & 44.4 & 48.24 & 0.07 & 0.49 & 0.47 & 1.73 & 0.27 \\
BMD & 60.09 & 34 & 0.02 & 0.32 & 0.13 & 0.14 & 0.07 \\
PEG & 54.15 & 44.06 & 0.15 & 0.18 & 0.31 & 0.53 & 0.11 \\
BEG & 42.59 & 46.2 & 0.03 & 0.43 & 0.14 & 0.23 & 0.98 \\
trunk & 75.86 & 20.45 & 0.2 & & 0.12 & 0.15 & \\
Ash rachis & 1.5 & & 21.5 & 2.8 & 1.69 & 3.53 & 6.79 \\
\hline
\end{tabular}

Table.4: medium value of quantification EDS tests for each variety and part of date palm samples from literary data (Agoudjil, 2011)

\begin{tabular}{|llllr|}
\hline \multicolumn{5}{|c|}{ Thermal and dielectric properties of date palm samples (petioles and bunches). } \\
\hline Reference & Fiber direction & $k\left[\mathrm{~W} \mathrm{~m}^{-1} \mathrm{~K}^{-1}\right]$ & $a\left[\times 10^{-7} \mathrm{~m}^{2} \mathrm{~s}^{-1}\right]$ & $\varepsilon_{\mathrm{r}}$ \\
\hline PDN & $\perp$ & $0.083 \pm 0.003$ & $2.29 \pm 0.20$ & $8.09 \pm 0.26$ \\
PMD & $\perp$ & $0.073 \pm 0.003$ & $3.13 \pm 0.49$ & $24.70 \pm 1.61$ \\
PEG & $\perp$ & $0.072 \pm 0.002$ & $2.76 \pm 0.24$ & $2.58 \pm 0.02$ \\
BDN & $\perp$ & $0.085 \pm 0.004$ & $1.91 \pm 0.21$ & $5.81 \pm 0.08$ \\
BMD & $\perp$ & $0.084 \pm 0.005$ & $2.07 \pm 0.30$ & $5.70 \pm 0.10$ \\
BEG & $\perp$ & $0.074 \pm 0.004$ & $2.29 \pm 0.30$ & $5.13 \pm 0.09$ \\
\hline
\end{tabular}

Table 5: Thermal conductivity coefficients obtained from research of Agoudjil et.al (Agoudjil, 2011)

It can be mentioned that adding the fibers decreases the thermal conductivity of the materials, and consequently increases the thermal resistance. This fact may present two interpretations: The first subject, has connection with the insulating properties of palm fibers, which has a low heat conductivity. The thermal conductivity of a compound object relies on those of inclusions which constitute it. The lower the thermal conductivity of inclusions, the more the composite is insulating. The second case is that the addition of natural fibers to strengthen building materials leads to an increase in the ratio of 
cavities and voids in them, led to a decline in the density of the composite and therefore its heat conductivity. Figure 18 shows the relationship between density and ratio of fibers to cornstarch in different specimens. From the above, it can be concluded that the natural fibers in industrial corn starch play an important role in improving thermal conductivity. Results with observations reported by several researchers such as: A. Oushabi et al, Negi et al, in their study on the effect of natural fibers on the thermal properties of concrete, and V. Hospodarova et al, in their research (HOSPODAROVA, 2017)

It can be seen from previous results, as the content of fibers increase in the specimen, the sample is made lighter in weight and the density decreases. however, the thermal resistance improves and creates the plant-based composite more eco-efficient by applying the best proportion. This is a desirable characteristic of ideal production sort and encourages various applying and use in the field. Although there is a determining relationship between thermal resistance and density, the quality of composites in terms of mechanical properties is the other substantial item that must be considered. The observations are in agreement with the results reported in the literature data. (DJOUDI, 2014) , (BEDERINA, 2007) According to the Figure 19, based on results, the density decreases with the increase in water absorption and swelling thickness percentage. Also, compared to the graph of water absorption and swelling thickness on the tenth day, the amount of thickness swelling is less than water absorption in specimen No.1 and No.2. Due to the fact that the higher the content of fibers, the higher the density and consistency of the sample would be, so, the lower the thickness swelling and distortion compared to water absorption percentage could be reasonable. However, by increasing the ratio of the fiber to matrix and decreasing the density consequently, the percentage of distortion and swelling thickness in the specimens No.6 and No.7 has increased compared to the percentage of water absorption. Among specimens, in No.3, No.4 and No 5, the percentage of thickness swelling and water is less than other samples. Considering the effect of coherence between resin and fibers in thickness swelling and water absorption percentage, this point can be mentioned that consistency and coherence between materials in these specimens are well established.

Totally, it can be mentioned that to have an optimal insulation, increasing the percentage of fibers to decrease the density in composite is not the only item that should be considered, but the coherence between the fibers and the matrix, the percentage of water absorption, swelling thickness, mechanical properties and resistance against moisture are the other important factors should be pointed out. To prevent mold in buildings in hot and humid climates, the humidity and temperature of the environment should be kept low. However, the materials proposed in the present study can be used both indoors and outdoors since they are protected with a surface of protective painting.

To continue the investigation of this subject can be mentioned:

- working to improve the penetration of the corn starch between fibers in order to fabricate plant-based composite with better mechanical properties.

- Other mechanical properties and IR-spectroscopy and the other strategies that can be used for assessing the quality of thermal conductivity and thermal diffusivity. 
- comprehensive study of the effects of composite moisture content on the mechanical features.

\section{Conclusion}

The number of people suffering from chemical allergies are increasing and natural building materials can help to reduce it. Formaldehyde and other chemicals are often used in the manufacture of construction products. The emission of these gases not only reduces the quality of indoor air but also their transfer to the open-air causes air pollution in the world and the environment. Choosing natural building materials without chemicals will lead to safer indoor air quality and reduced health risks for homeowners.

Some resources are renewable (such as trees and fibers) and some are so abundant that they are considered almost inexhaustible (such as rock and soil). These local natural materials require less processing or transportation and their economic and environmental costs are low. Therefore, by adapting these materials to today's technical and engineering requirements, they can be used to provide housing for low-income people. For sustainable development, it is necessary to distribute limited local financial resources within and among the locals instead of leaving the area. Also, technical knowledge in various fields, including construction in the region, should be expanded and maintained. On the other hand, ecofriendly materials give the building an "indigenous" quality or a sense of belonging to the place, which is pleasant. In this article, date palm fibers, which is one of the most widely used ecological materials that can be applied in Iran, were studied as a thermal insulation. After experimental testing of fibers, obtaining the chemical composition of its constituents by EDS, investigation of seven samples in terms of water saturation and swelling properties and thermal resistance test, the optimal insulation sample was obtained. Considering the proposed factors mentioned in this study, combining the same volume ratio of date palm fibers with industrial corn starch, the best specimen was experimentally obtained. The result showed no changes in heat transfer by using the composite, the eco-friendly material, in maximum temperature up to $80^{\circ} \mathrm{C}$. This result shows that date palm fibers have a positive effect on energy optimization in buildings.

\section{Declarations}

The authors declare that they have no known competing financial interests or personal relationships that could have appeared to influence the work reported in this paper.

\section{Acknowledgments:}

We are thankful to Dr. Nasser Varahram who provided expertise that greatly assisted the research. His consulting moderated this paper and improved it significantly.

We are also immensely grateful to Dr. Shahryar Habibi for sharing their pearls of wisdom with us during the course of this research, although any errors are our own and should not tarnish the reputations of these esteemed professionals. 


\section{References}

A.M.PapadopoulosE.Giama, 2006. Environmental performance evaluation of thermal insulation materials and its impact on the building. Building and environment, pp. 2178-2187.

Abdelazizab, S., 2016. Date palm spikelet in mortar: Testing and modelling to reveal the mechanical performance. Construction and Building Materials, Volume 124, pp. 228-236.

Adam, N. \& Asik, J., 2019; . Mechanical performance of oil palm empty fruit bunches fibre reinforced polyester resin. In IOP Conference Series:. Materials Science and Engineering; Volume 469.

Adekomaya, O. \& Adama, K., 2018. Investigating water absorption and thickness swelling tendencies of polymeric composite materials for external wall application in refrigerated vehicles.. Niger. J.

Technol., Volume 37, p. 167-172.

Agoudjil, B., 2011. Renewable materials to reduce building heat loss: Characterization of date palm wood. Energy and Buildings, pp. 491-497.

Al-Maharma, A. \& Al-Huniti, N., 2019. Critical Review of the Parameters Affecting the Effectiveness of Moisture Absorption Treatments Used for Natural Composites. J. Compos. Sci. , Volume 3, p. 27.

al, S. E. e., 2013. Effect of reinforced system by palm fibers on the mechanical properties for polymer composite materials. Eng. \& Tech. Journal, Vol.31, No.2 .

Alshabanat, M., 2019. Morphological, thermal, and biodegradation properties of LLDPE/treated date palm waste composite buried in a soil environment. Journal of Saudi Chemical Society, Volume 23, pp. 355364.

Azami, A., 2015. Investigation of tensile and flexural properties of date palm fiber reinforced gypsum. Tehran, Shahid Beheshti University.

B. Beighi, F. J., 1998. Research and report on the use of palm products in the industry.First step is to identify areas prone palm.. Industry Direction General of Kerman province.

Barsam, M., 2019. A comparative study of defense and security fortifications, Rhine and Bam Citadel in Kerman Province. Parseh Journal of Archeological Studies.

BEDERINA, M. -. M. L. -. M. K. -. K. M. M. -. B. A. -. Q., 2007. : Effect of the addition of wood shavings on thermal conductivity of sand concretes, experimental study and modelling. Construction and Building Materials, Volume 21, p. 662-668.

Benaimeche, O. et al., 2018. The influence of date palm mesh fibre reinforcement on flexural and fracture behaviour of a cement-based mortar.. Composites Part B: Engineering, pp. 292-299. 
Cao, X., 2016. Building energy-consumption status worldwide and the state-of-the-art technologies for zero-energy buildings during the past decade. Energy and buildings, p. 128.

Chikhi, M., 2016. Young's modulus and thermophysical performances of bio-sourced materials based on date palm fibers. Energy and buildings, pp. 589-597.

D570-98, A., 2018. Standard Test Method for Water Absorption of Plastics, West Conshohocken,PA: ASTM International,.

Dayo, A. et al., 2018. The influence of different chemical treatments on the hemp fiber/polybenzoxazine based green composites: Mechanical, thermal and water absorption properties..

Mater.chem.phys, Volume 217, pp. 270-277.

Djoudi, A., 2014. Effect of the addition of date palm fibers on thermal properties of plaster concrete: Experimental study and modeling. Jornal of Adhesion Science and Technology.

DJOUDI, A. K. M. M. B. A. B., 2014. Effect of the addition of date palm fiberson thermal properties of plaster concrete, experimental study and modeling. Adhesion Science and Technology, Volume 28, pp. 2100-2111.

Dr. Sihama E.Salih, H. A. A.-K. S. I., 2013. Effect of Reinforced System by Palm Fibers on the Mechanical and Insulation (Thermal and Acoustic) Properties for Polymer Composite Materials. Eng \& Tech Journal, Volume 31.

Edhirej, A., Sapuan, S., Jawaid, M. \& Zahari, N., 2017. Cassava/sugar palm fiber reinforced cassava starch hybrid composites: Physical, thermal and structural properties.. Int. J. Biol. Macromol, Volume 101, p. 7583.

EisakuOho, 1998. Digital Image Processing Technology for Scanning Electron Microscopy. Advances in Imaging and Electron Physics, Volume 105, pp. 77-112, 112a, 112b, 112c, 112d, 113-140.

Gheith, M. et al., 2019. Flexural, thermal and dynamic mechanical properties of date palm fibres reinforced epoxy composites. Journal of Materials Research and Technology, Volume 8, pp. 853-860.

HOSPODAROVA, V. -. S. N. -. V. V. -. D. T., 2017. Influence of Cellulosic Fibres on the Physical Properties of Fibre Cement Composites. Materials Science and Engineering, Volume 251, pp. 1-9.

Ibrahim, H., Farag, M., Megahed, H. \& Mehanny, S., 2014. . Characteristics of starch-based biodegradable composites reinforced with date palm and flax fibers.. Carbohydrate Polymers, Volume 101, pp. 11-19.

Jarratt, D. M. P. a. M., 2000. Thermal conductivity of PTFE and PTFE composites. Society, pp. 579-584.

K.I.Alzebdeh, 2017. Characterization of Mechanical Properties of Aligned Date Palm Frond FiberReinforced Low Density Polyethylene. The Journal of Engineering Research (TJER) , pp. 115-123. 
Kashizadeh, R., 2019. Physico-mechanical and thermal properties of date palm fiber/phenolic resin composites. Polymer Composites, pp. 3657-3665.

M.Karizaki, V., 2017. Iranian dates and ethnic date-based products. Journal of Ethnic Foods, pp. 204-209.

Mirmehdi, S., Zeinaly, F. \& Dabbagh, F., 2014. Date palm wood flour as filler of linear low-density polyethylene.. Compos. Part B Eng, Volume 56, p. 137-141.

Mourad, C., 2013. Experimental investigation of new biocomposite with low cost for thermal insulation. Energy and Buildings , pp. 267-273.

Negawo, T. et al., 2019. Mechanical, morphological, structural and dynamic mechanical properties of alkali treated Ensete stem fibers reinforced unsaturated polyester composites.. Compos. Struct., p. 20.

Oushabi, A., 2015. Natural thermal-insulation materials composed of renewable resources:characterization of local date palm fibers (LDPF). Jornal of Materials and Environmental Science, pp. 3395-3402.

Peter F. Infante DDS, D. L. D. S. P. J. D. C. P. J. H. P., October 1994. Fibrous glass and cancer. American journal of industrial medicine.

Razak, N. \& Anizah, K., 2012. Effect of OPEFB size on the mechanical properties and water absorption behaviour of OPEFB/PPnanoclay/PP hybrid composites.. Procedia Eng, Volume 41, p. 1593-1599. .

Russell, C., 1973. Industrial use of cornstarch. Journal Articles, USDA Authors, Peer-Reviewed, pp. 262284.

Senthilkumar, K. et al., 2019. Evaluation of mechanical and free vibration properties of the pineapple leaf fibre reinforced polyester composites.. Constr. Build. Mater, Volume 42, p. 195.

Shalwan, A. \& Yousif, B., 2014. Influence of date palm fibre and graphite filler on mechanical and wear characteristics. Mater. Des, Volume 59, pp. 264-273.

Steffensa, F., 2017. Applications of Natural Fibers On Architecture, , 2017. Jornal of Procedia Engineering.

Union, E., 1999 . Annual Report EU-OSHA, s.l.: s.n.

Wei, L., McDonald, A., Freitag, C. \& Morrell, J., 2013. Effects of wood fiber esterification on properties, weatherability and biodurability of wood plastic composites.. Polym. Degrad, Volume 98, p. 1348-1361.

Wet.FAO, A. Z. a. P. d., 2018. FAO. [Online]

Available at: http://www.fao.org/3/Y4360E/y4360e06.htm

Wiley, J., 2015. Energy Dispersive Spectroscopy. Southern Gate, Chichester, West Sussex, P019 8SQ: Essential knowlegde breifings. 
Zaid, A., 2002. Date Palm Cultivation. Rome: FOOD AND AGRICULTURAL ORGANIZATION OF THE UNITED NATIONS.

\section{Figures}

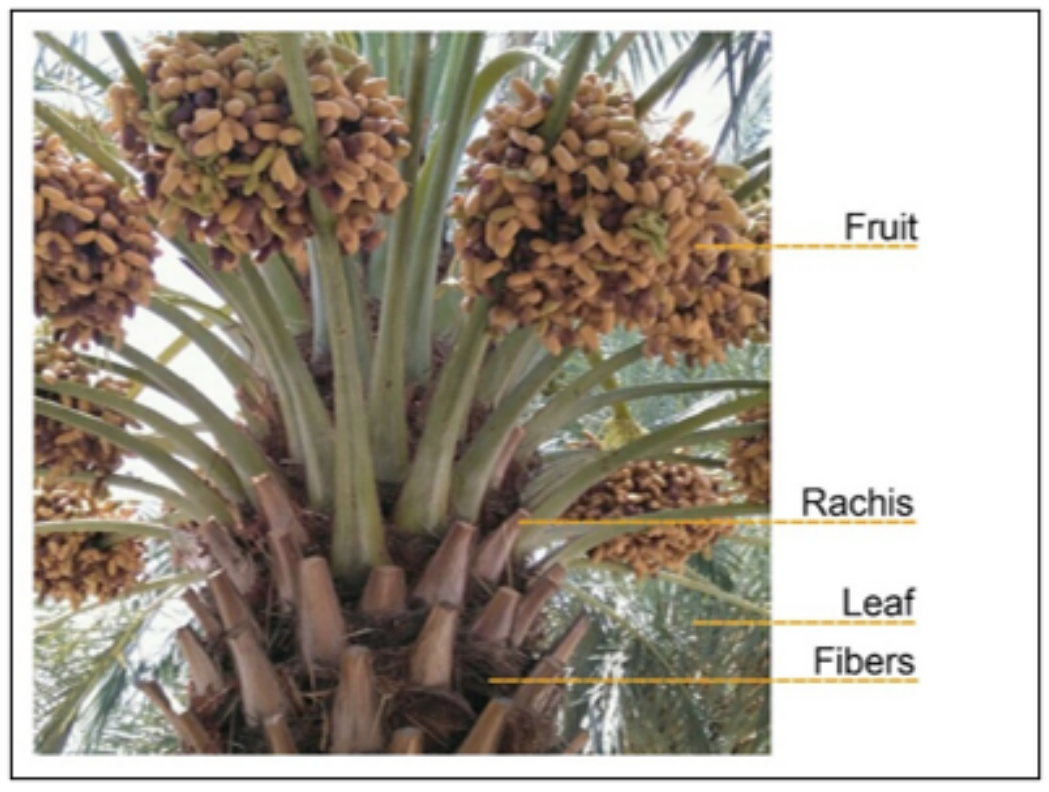

Figure 1

Details of date palm tree

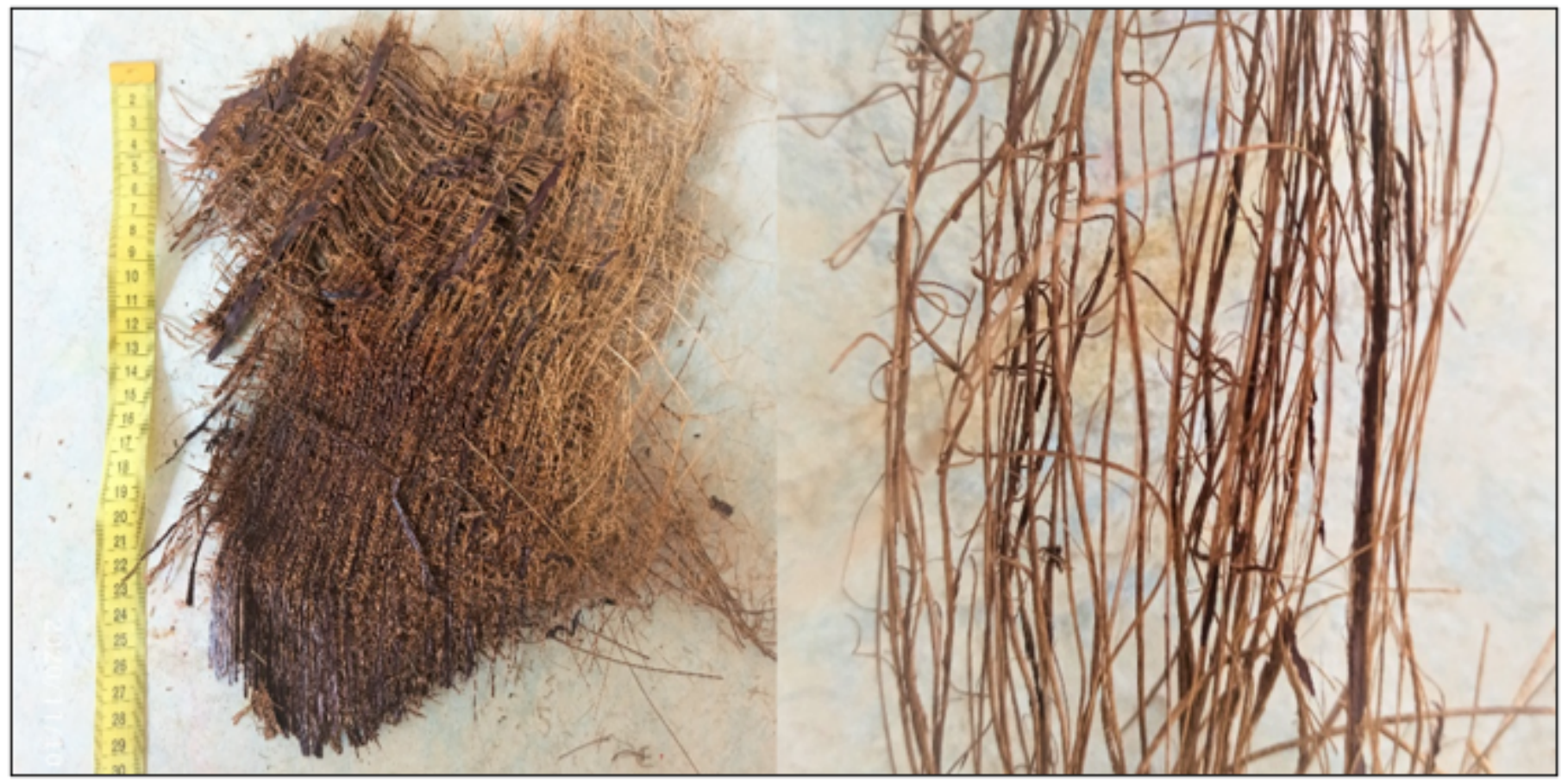

Figure 2 
Date palm fibers with approximately 20 to $30 \mathrm{~cm}$ width and Separated date palm fibers with dimeters of 0.1 to $0.8 \mathrm{~mm}$

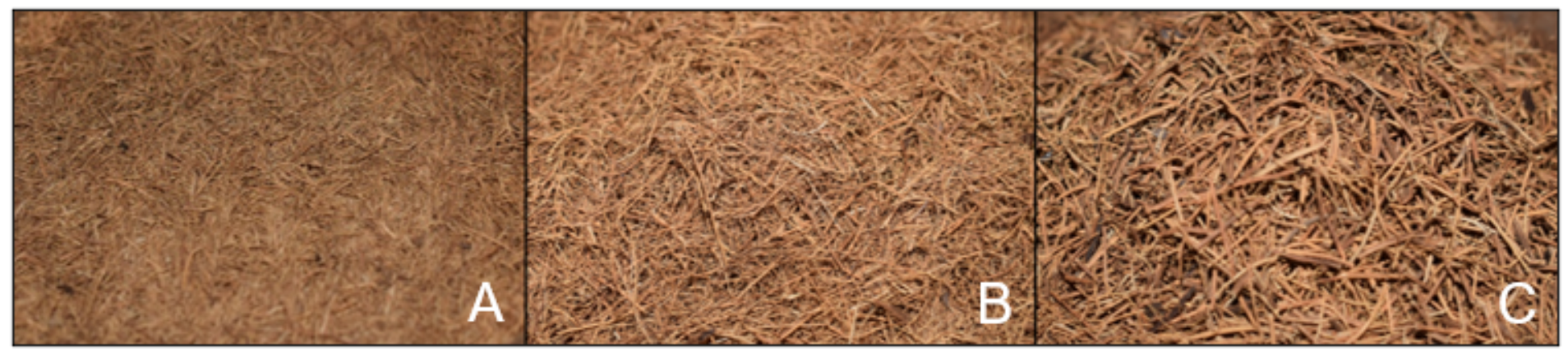

\section{Figure 3}

Date palm fibers in different sizes of $20 \mathrm{~mm}, 50 \mathrm{~mm}$ and $100 \mathrm{~mm}$ respectively from A to C. According to the table 2, the length of $20 \mathrm{~mm}(\mathrm{~A})$ was used in preparing seven samples due to high modulus of elasticity.
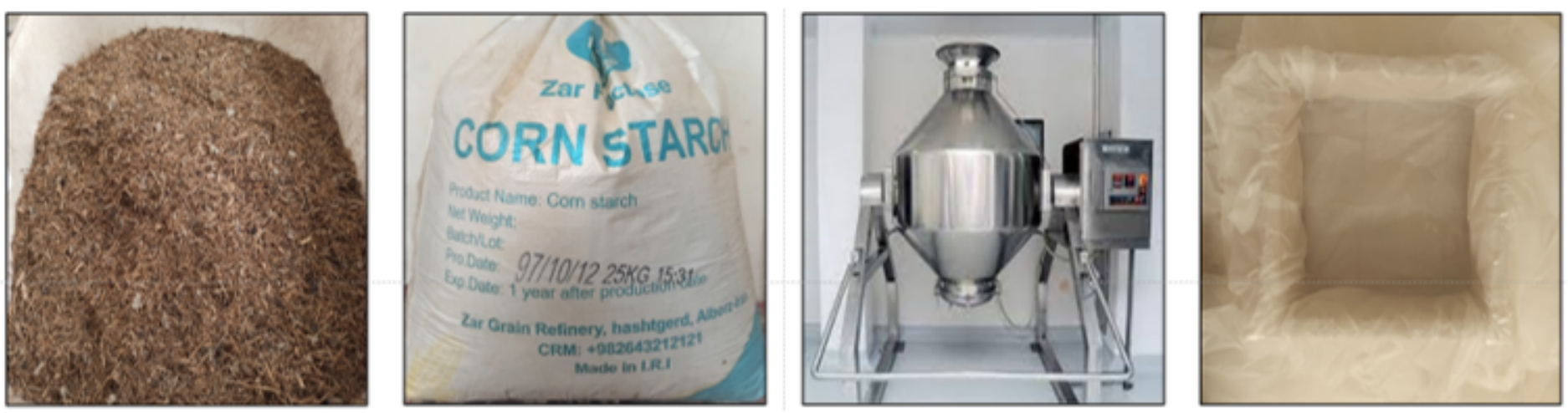

\section{Figure 4}

Requirement for making specimens: Date palm fibers, Corn starch, Mixer, Molding container. 


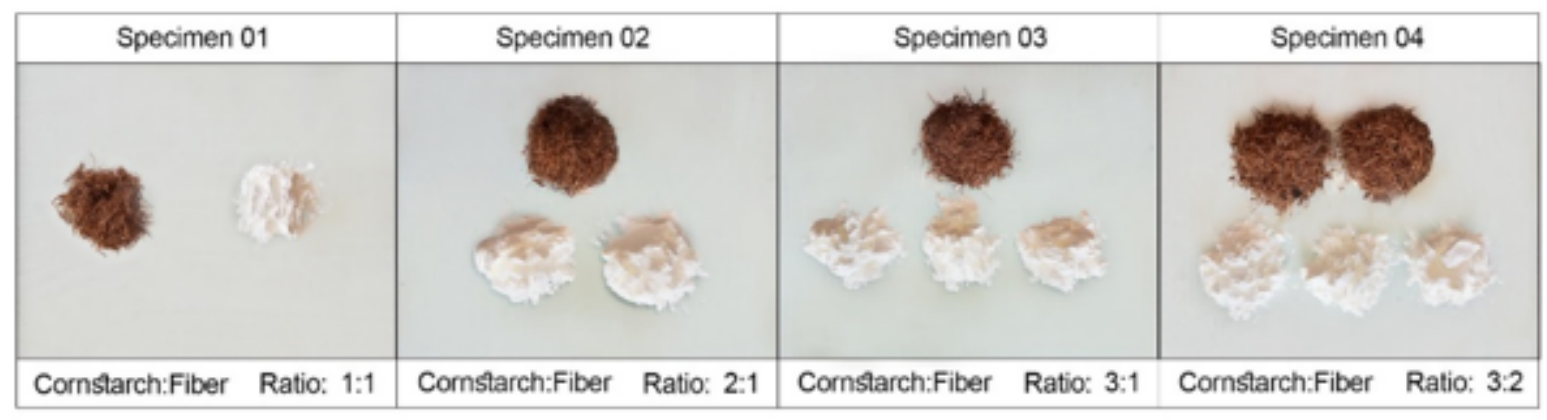

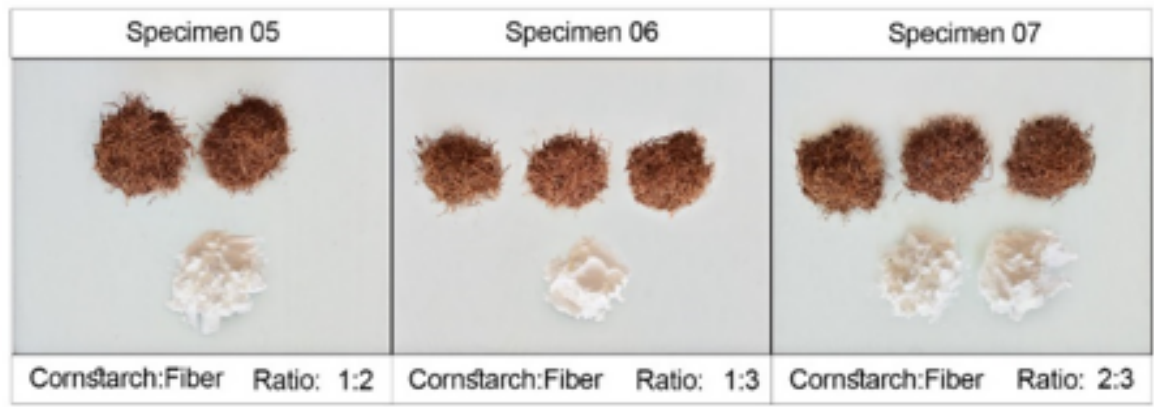

\section{Figure 5}

Prepared sample in deferent proportion.

\section{Figure 6}

Sample of specimen procedure (ratio 1:1), According to the table 3.

\section{Figure 7}

Comparison between fiber content in the specimens and density $(\mathrm{kg} / \mathrm{m} 3) / 100$.

\section{Figure 8}

Environmental Testing Chambers - ETC in Razi metallurgical research center.

\section{Figure 9}

Nova Nano SEM 450 for scanning electron microscope (SEM) 


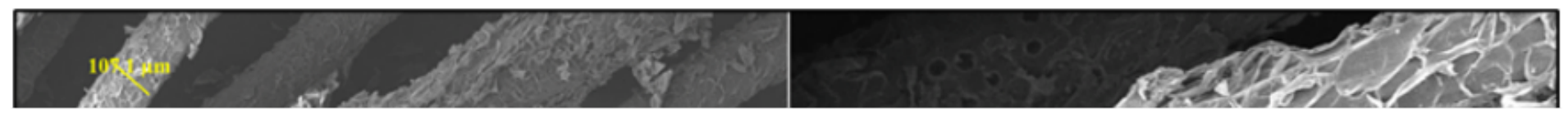

Figure 10

SEM images of a sample Zahedi-DPF in a longitudinal direction of fibers is scales from 500 to $5 \mu \mathrm{m}$

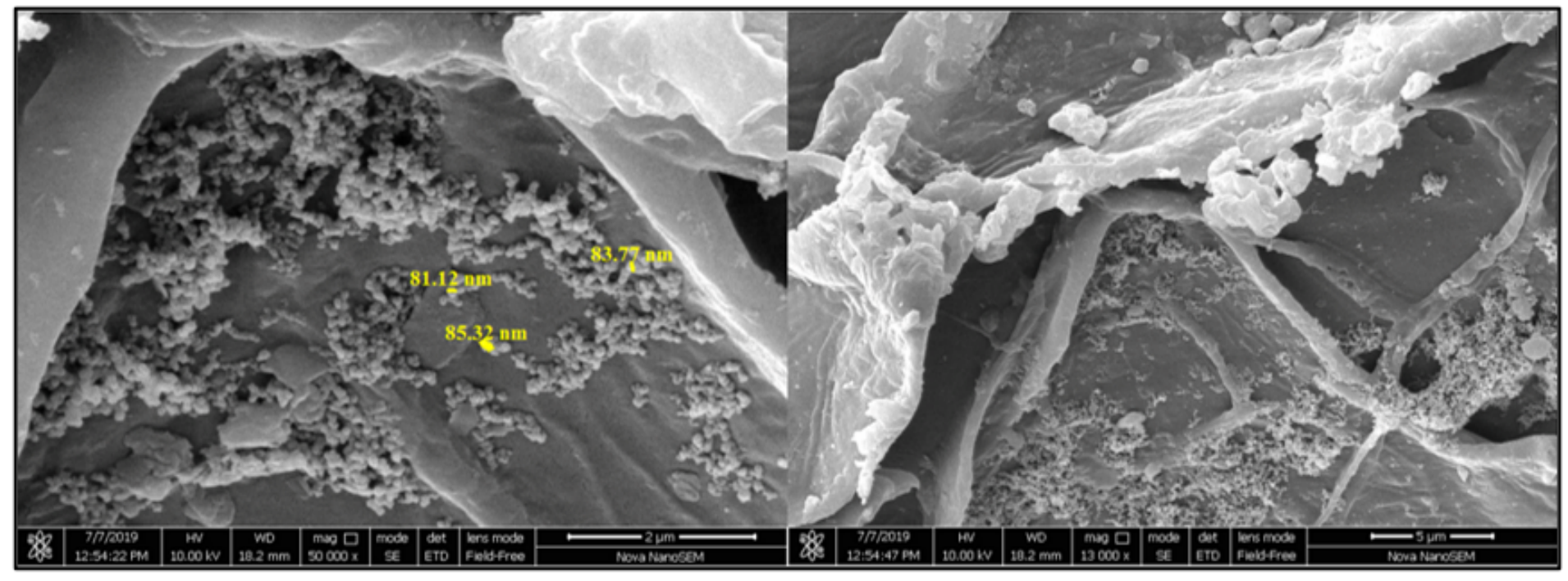




\section{Figure 11}

Surface of the samples in scale of 5 and $2 \mu \mathrm{m}$.

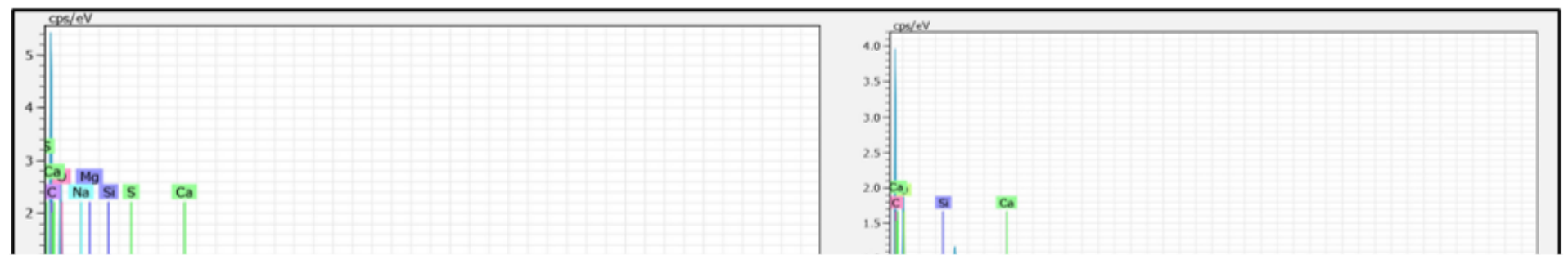

Figure 12

The result of EDS test of Zahedi-DPF

Figure 13

Water absorption tendencies of plant-based composite. Horizontal axis: Immersion (day), Vertical axis: Water absorption (\%) 


\section{THICKNESS SWELLING}

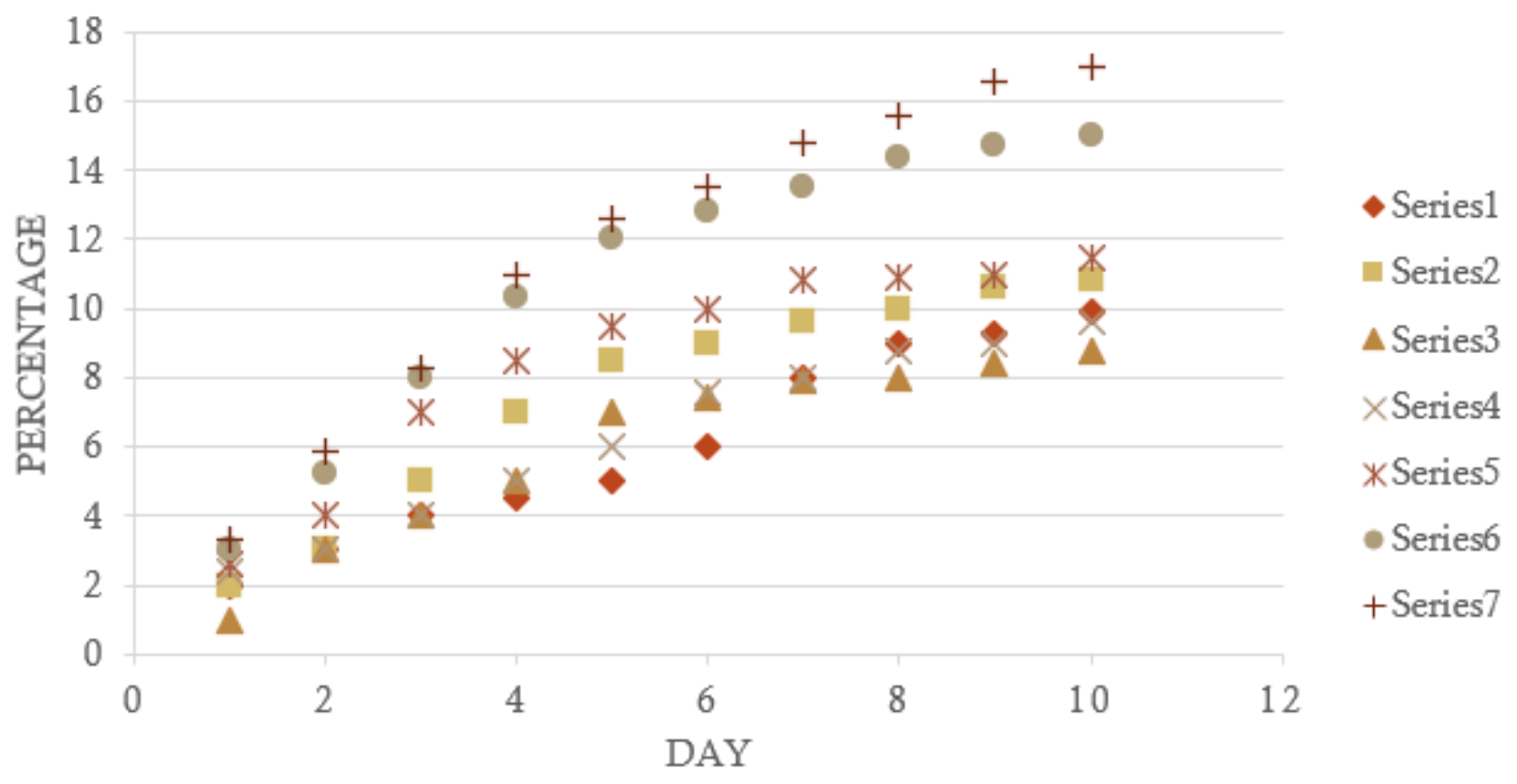

\section{Figure 14}

Thickness swelling test. Horizontal axis: Immersion (day), Vertical axis: Thickness swelling (\%)

\section{Figure 15}

Results of thermal resistance test for selected specimens № 1, No 4, No 7.

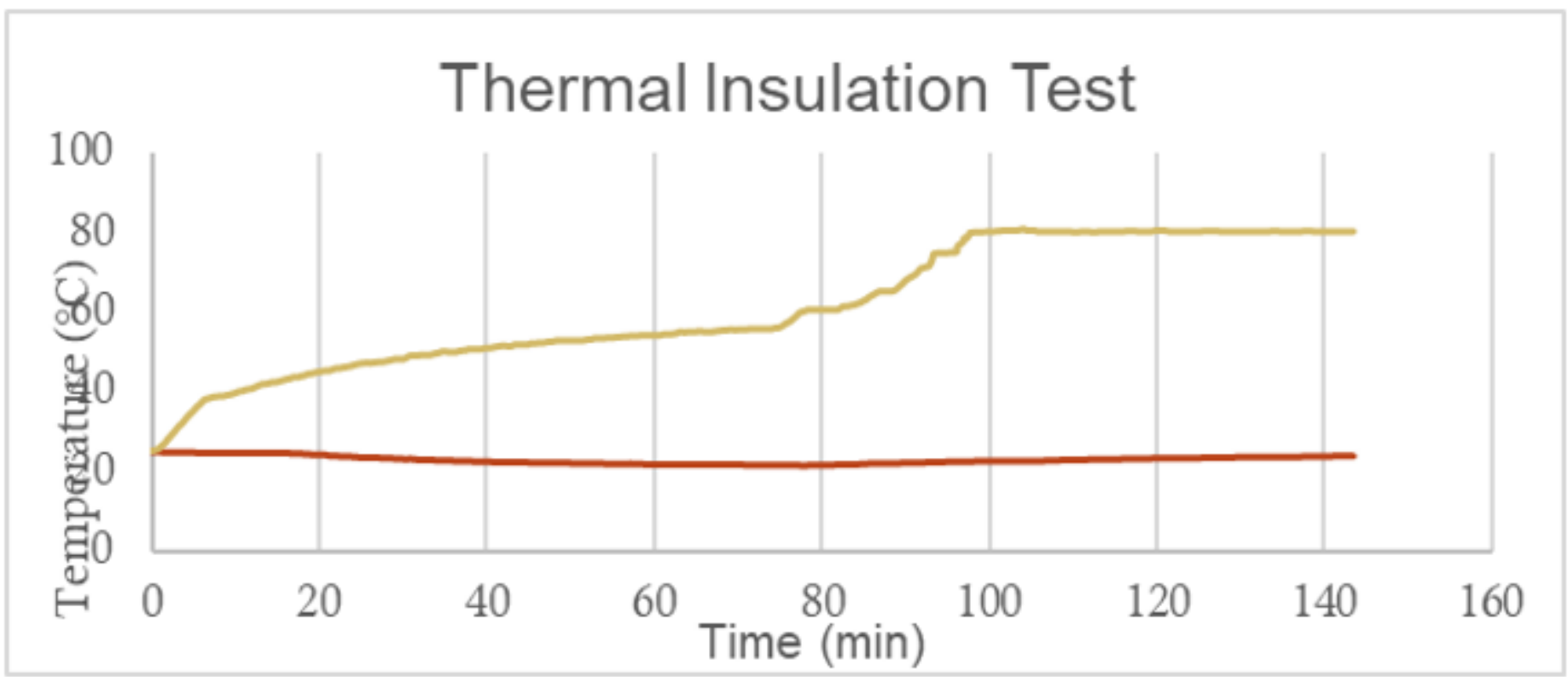


Figure 16

The result of thermal resistance test on specimen No.4.

Figure 17

Comparison between EDS test of Zahedi-DPF and samples from literary data

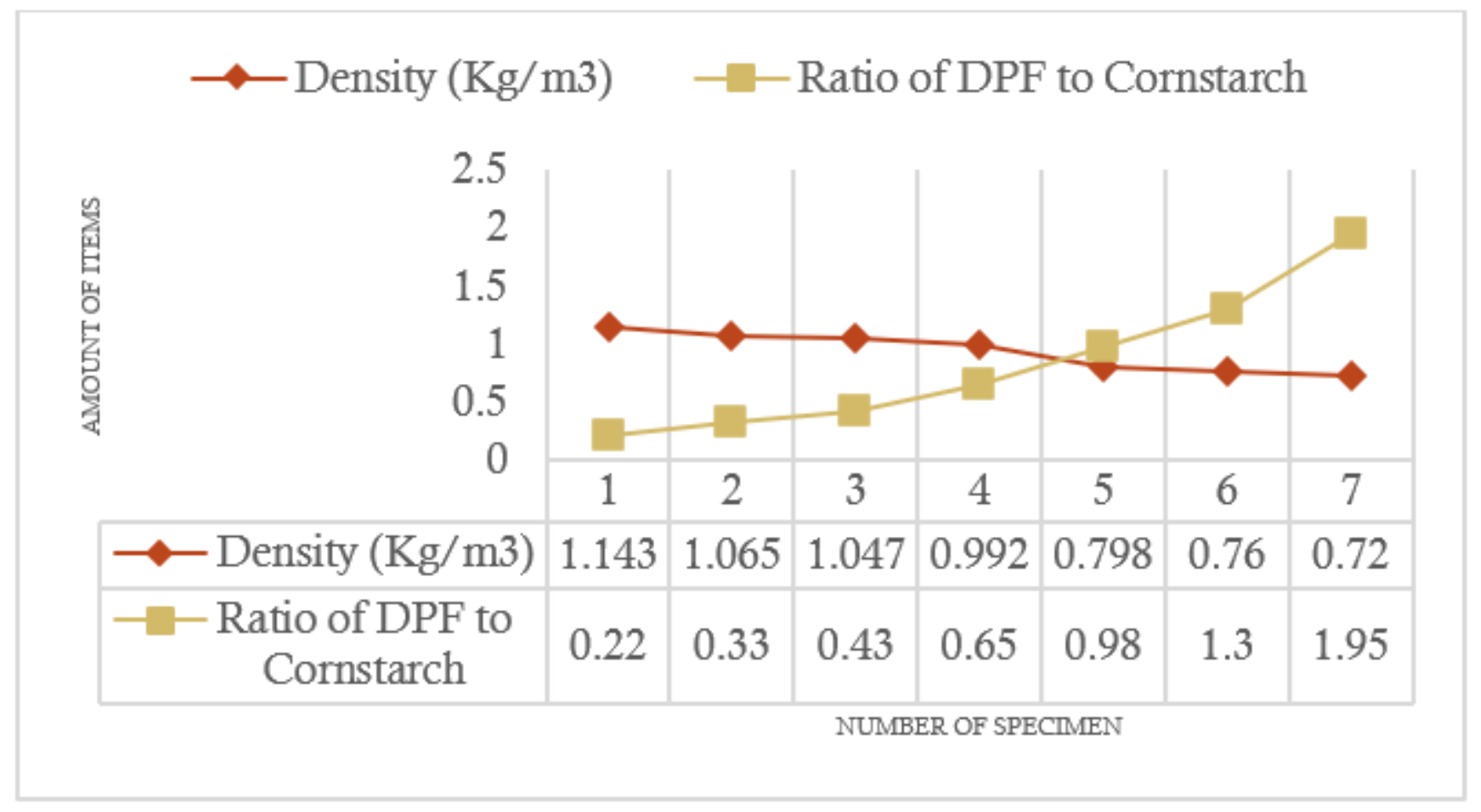

Figure 18

Relationship between Density and content of date palm fiber. 


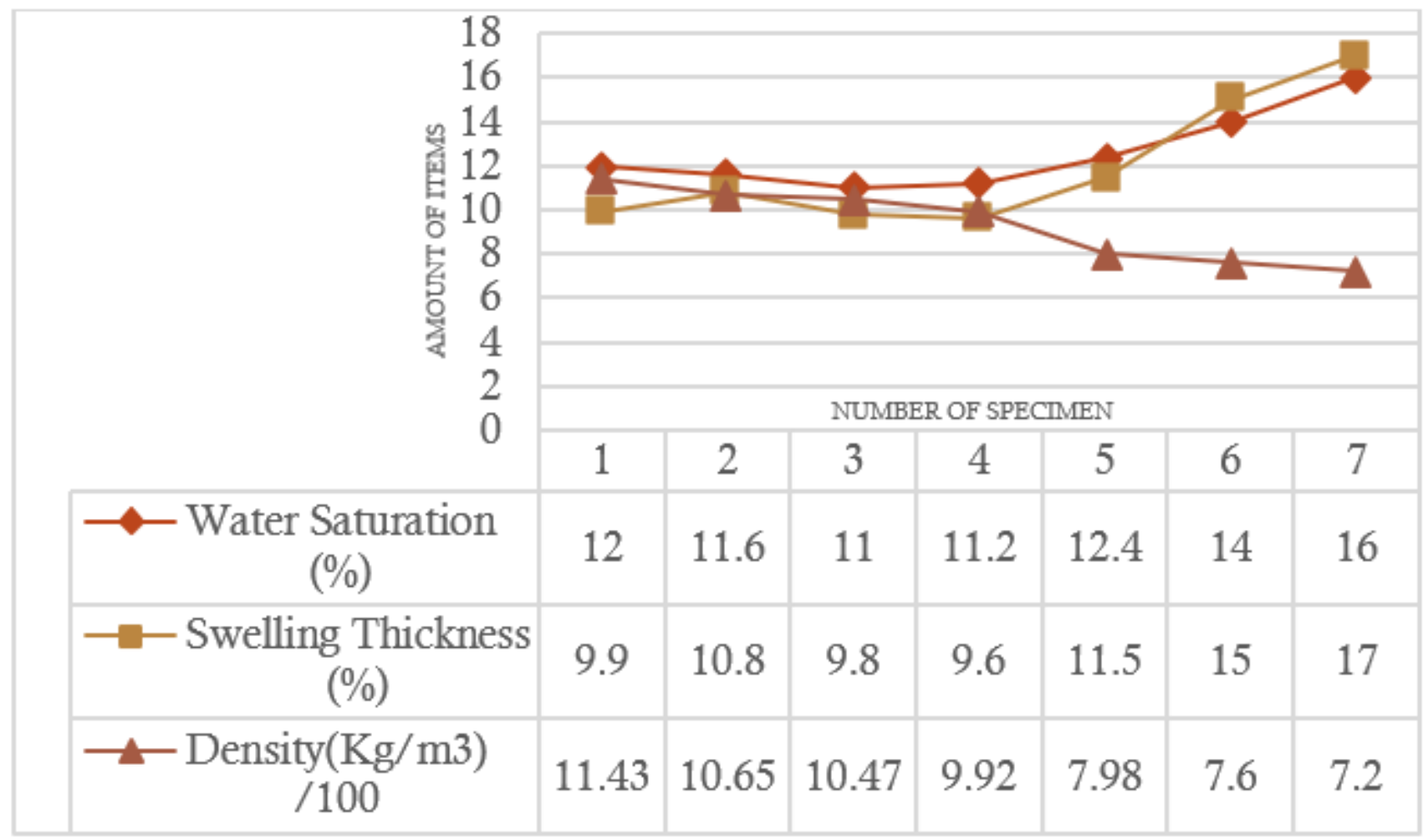

Figure 19

Comparison with density, swelling thickness, water saturation. 